\title{
Applicability of a Simplified SDOF Method in Longitudinal Deck-Pier Poundings of Simply Supported Girder Bridges
}

\author{
Tianbo Peng ${ }^{1,2}$ and Ning Guo ${ }^{1,2}$ \\ ${ }^{1}$ State Key Laboratory of Disaster Reduction in Civil Engineering, Tongji University, Shanghai 200092, China \\ ${ }^{2}$ College of Civil Engineering, Tongji University, Shanghai 200092, China \\ Correspondence should be addressed to Tianbo Peng; ptb@tongji.edu.cn
}

Received 2 January 2016; Accepted 20 March 2016

Academic Editor: Stefano Sorace

Copyright (C) 2016 T. Peng and N. Guo. This is an open access article distributed under the Creative Commons Attribution License, which permits unrestricted use, distribution, and reproduction in any medium, provided the original work is properly cited.

\begin{abstract}
The pounding issue between decks in the earthquake has been a great concern of many researchers, but the research on the deckpier pounding issue was inadequate. In this paper, a simplified SDOF method was proposed to study the issue for simply supported girder bridges. Theoretical analysis, shaking table test, and finite element analysis were conducted to study the applicability of the simplified SDOF method in longitudinal deck-pier poundings. A whole structural model and a SDOF model for the longitudinal pounding issue were also established to study influences of the pier stiffness and the pier mass on longitudinal pounding responses. It is shown that the simplified SDOF method can estimate the pounding force and deck displacement fairly accurately for almost all cases. The pier mass has little effect on pounding responses except for bridges with very rigid piers, but the pier stiffness has a great influence. The larger the pier stiffness is, the higher the peak pounding force is.
\end{abstract}

\section{Introduction}

The pounding issue of bridges under earthquakes has been a research focus studied by a lot of scholars in recent years. Some kinds of classical methods were proposed for the issue. For example, stereo mechanical approach $[1,2]$, which is a theoretical approach based on momentum conservation theorem of two particles, was used by several researchers. In stereo mechanical approach, the coefficient of restitution (COR) was used to represent the ratio of speeds after and before an impact. Pairs of particles with COR $=1$ collide elastically, while particles with COR $<1$ collide inelastically. For a $\mathrm{COR}=0$, the particles effectively "stop" at the pounding. The concept of the approach is simple and complicated calculations are avoided. However, a main shortcoming is that the pounding time must be very short to neglect effects of other forces in the pounding process.

Compared with the stereo mechanical approach, several kinds of contact element methods were more often used for their convenience for commercial finite element software [3]. In these methods, the impact of two pounding objects is simulated by a contact element inserted between the two objects. These methods have been improved a lot in order to simulate different types of poundings. Contact element methods include several kinds of models, such as linear spring model, Kelvin model, Hertz model, and Hertz damping model. These models have been widely used to investigate pounding responses of buildings and bridges [413]. Contact elements are built by springs, dampers, and gaps by series-parallel connections. The concept of contact element method is clear and different types of poundings can be simulated using a variety of models. Pounding force can be calculated using finite element software easily.

Goldsmith suggested a one-dimensional wave method to study the pounding issue theoretically [1]. Based on the method, Watanabe and Kawashima proposed a contact element method to simulate the coaxial pounding issue between adjacent decks [14]. Parametric analyses of mesh density and stiffness of the contact element were conducted, and it was found that results obtained by FEM and by the one-dimensional wave method would be very close if the stiffness of the contact element was close to the axial stiffness between two adjacent particles after meshing of the deck. And it was also found that the finer the meshing of the deck was, 


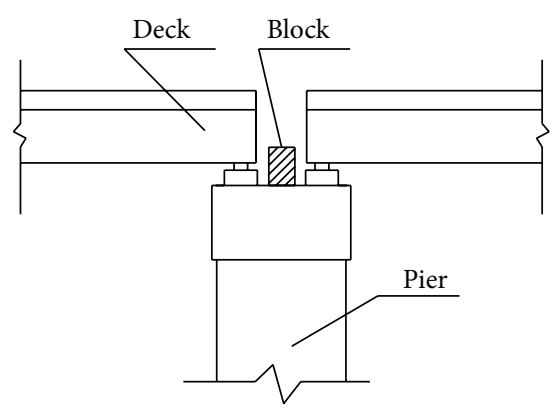

(a) Pounding between decks and blocks

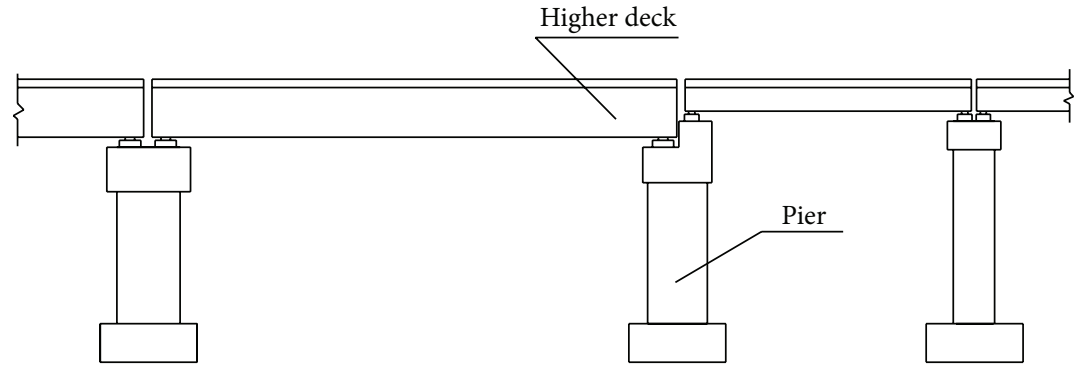

(b) Pounding between the higher deck and the pier top

Figure 1: Examples related to the deck-pier pounding issue.

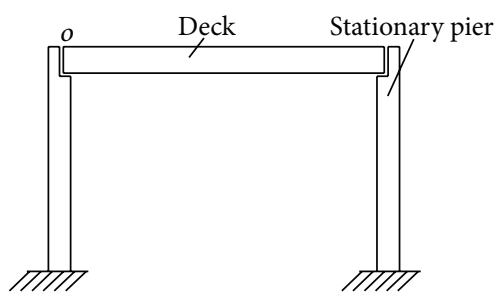

(a) Deck-pier pounding issue

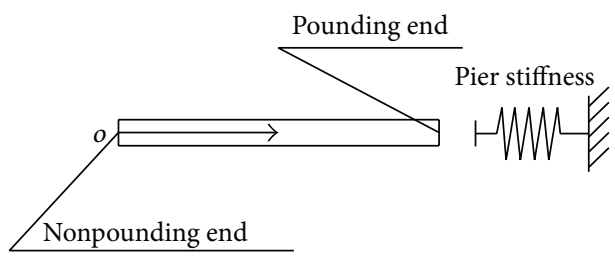

(b) A one-dimensional wave theoretical model

Figure 2: A one-dimensional wave theoretical model for the deck-pier pounding issue.

the closer the results obtained by FEM were to the results obtained by the one-dimensional wave method.

Up to now, many researches were focused on poundings between the bridge deck and the abutment. Dimitrakopoulos proposed a novel nonsmooth rigid body approach to analyze seismic responses of pounding skew bridges which involved oblique frictional multicontact phenomena [15]. Li et al. evaluated influences of abutment excitations on the pounding behavior of a system consisting of a single bridge span with various fundamental frequencies and its abutments experimentally [16]. Wang and Shih presented a case study on the sliding of bridge decks of a multispan concrete bridge and pounding at abutment-backfill under the $1999 \mathrm{Chi}-\mathrm{Chi}$ earthquake [17]. Huo and Zhang studied effects of pounding and skewness on the seismic behaviors of typical three-span bridges in California [18].

There were also many researches on poundings between bridge decks. Bi and Hao performed numerical simulations of pounding damage between bridge decks based on a detailed 3D finite element model [19]. Abdel Raheem developed an analytical model of expansion joints considering the interaction between adjacent bridge segments and the effect of impact and restrainers [20]. Li and Chouw studied the inelastic response of a two-segment bridge due to spatially varying ground motion including pounding using shake tables [21]. Kim and Shinozuka studied the effect of pounding at expansion joints on concrete bridge response to earthquake ground motions [22].
However, there is little research on the deck-pier pounding issue, but this kind of phenomenon was far from rare. For example, decks and unseating prevention blocks on piers would collide with each other in the longitudinal and transverse directions in earthquakes, as shown in Figure 1(a) [23].

Another example is related to a pier supporting two decks with different heights. The higher deck will hit the pier top in the longitudinal direction, as shown in Figure 1(b).

Because of the flexibility of piers, the deck-pier pounding issue is different from the pounding issue between decks or that between the bridge deck and the abutment, so pounding responses should receive adequate attention.

Taking a simply supported girder bridge as an example, the deck-pier pounding issue in the longitudinal direction is studied using two theoretical methods at first in this paper. According to the findings, a simplified single degree of freedom (SDOF) model is established and verified by shaking table test method. At last, influences of the pier stiffness and the pier mass on pounding responses of a simply supported girder bridge were studied by finite element method.

\section{Theoretical Analysis of the Deck-Pier Pounding Issue}

Two theoretical models are used in this section to simulate the pounding between a deck with an initial velocity and the top of a stationary pier as shown in Figure 2(a). The first model is 


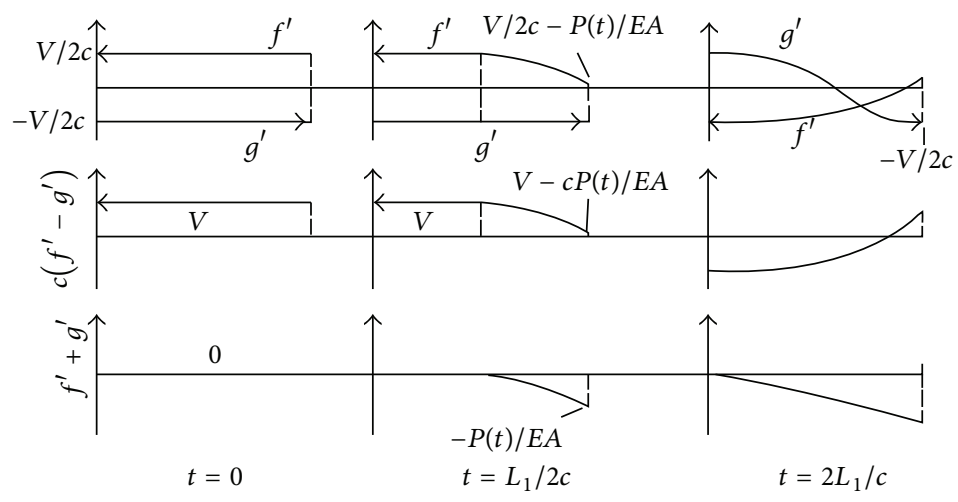

FIGURE 3: Waveforms of the first-order derivatives of $f$ and $g$.

based on the one-dimensional wave theory which had been successfully applied on the deck-deck pounding issue [1]. The influence of the pier mass on pounding responses is neglected for the possibility of solving differential equations. So the theory is not applicable for very tall or heavy piers. In the onedimensional wave theory, the deck mass and pier flexibility are considered. The model is shown in Figure 2(b). Suppose that piers are not damaged during the pounding; the pier stiffness is a constant.

Physical meanings of parameters in the theoretical analysis are as follows:

$E, A, L$, and $\rho$ are elastic modulus, cross-sectional area, length, and density of the deck, respectively.

$V$ is the initial velocity of the deck before pounding.

$P(t)$ is the time history of the pounding force.

$\beta$ is the ratio of the horizontal stiffness of bridge pier to the axial stiffness of the deck.

$k_{p}=\beta E A / L$ is the horizontal stiffness of bridge pier. $u(x, t)$ is the displacement of the particle which is at a distance of $x$ from the nonpounding end of the deck at time $t$. According to the one-dimensional wave theory, $u(x, t)=f(x+c t)+g(x-c t)$. And $f$ and $g$ are displacement waves propagating in the positive and negative directions, respectively. $f^{\prime}$ and $g^{\prime}$ are the first-order derivatives of $f$ and $g . c=\sqrt{E / \rho}$ is the propagation velocity of the displacement wave.

The model shown in Figure 2(b) is analyzed theoretically using the one-dimensional wave theory. According to initial conditions that the initial velocity is $V$ and the initial strain is zero when $t=0$, we have

$$
\begin{gathered}
\frac{\partial u(x, t)}{\partial t}=c\left(f^{\prime}-g^{\prime}\right)=V \\
\frac{\partial u(x, t)}{\partial x}=f^{\prime}+g^{\prime}=0
\end{gathered} \quad \Longrightarrow f^{\prime}=-g^{\prime}=\frac{V}{2 c} .
$$

According to the boundary condition that the strain is zero at $x=0$, we have

$$
f^{\prime}=-g^{\prime}
$$

According to the boundary condition that the strain is $-P(t) / E A$ at $x=L$, we have

$$
f^{\prime}=-\frac{P(t)}{E A}-g^{\prime}
$$

According to the one-dimensional wave theory, the firstorder derivatives of displacement wave equations can be shown in Figure 3. The wave equations of the nonpounding end and the pounding end are determined based on (2) and (3).

For $t \in[0,2 L / c]$, the velocity time history at $x=L$ is as follows:

$$
\begin{aligned}
\frac{\partial u(L, t)}{\partial t} & =-c f(L, t)+c g(L, t)=V-\frac{c}{E A} P(t) \\
& =V-\frac{\beta c}{L} u(L, t) .
\end{aligned}
$$

Solving the differential equations, we have

$$
u(L, t)=\frac{V L}{\beta c}\left[1-\exp \left(\frac{-\beta c t}{L}\right)\right] .
$$

And the time history of the pounding force is

$$
P(t)=\frac{E A V}{c}\left[1-\exp \left(\frac{-\beta c t}{L}\right)\right] .
$$

For $t \in[2 L / c, 4 L / c]$, the velocity time history at $x=L$ is as follows:

$$
\begin{aligned}
\frac{\partial u(L, t)}{\partial t}= & V-\frac{c}{E A} P(t)-\frac{2 c}{E A} P\left(t-\frac{2 L}{c}\right) \\
= & V-\frac{\beta c}{L} u(L, t) \\
& -2 V\left[1-\exp \left(\frac{-\beta c t}{L}+2 \beta\right)\right] .
\end{aligned}
$$




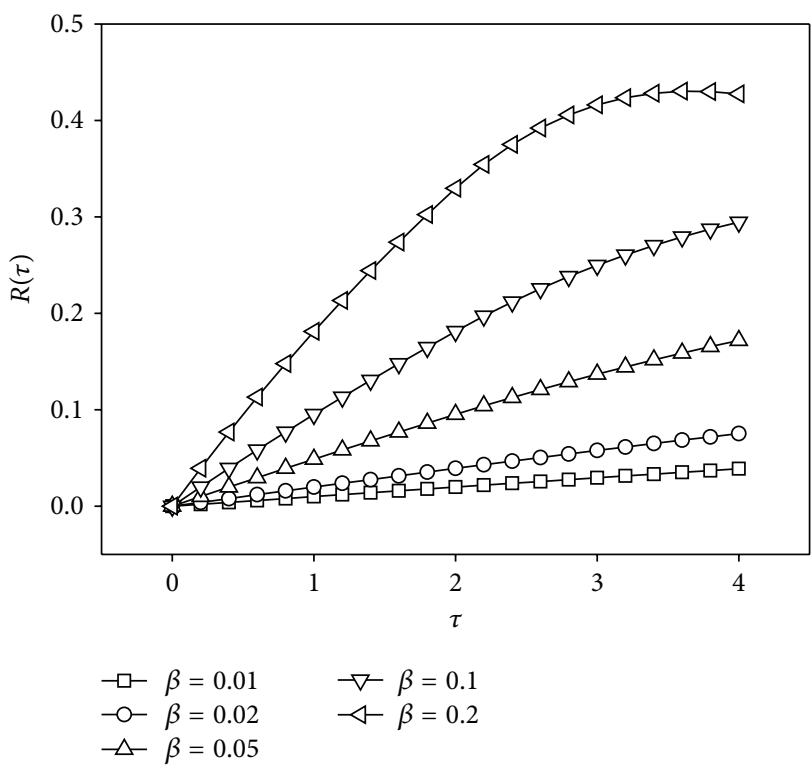

(a)

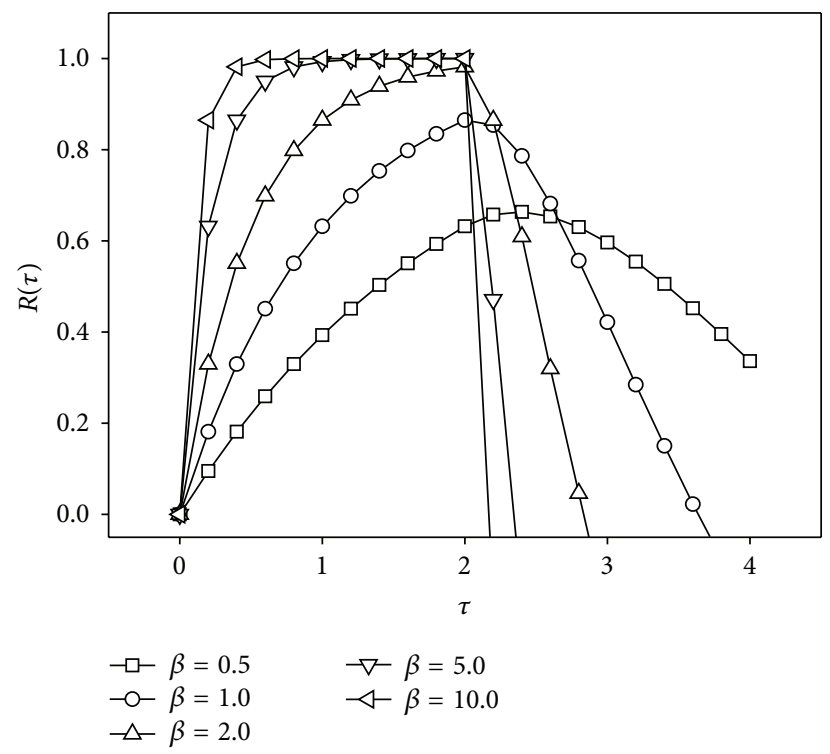

(b)

FIGURE 4: Time histories of the deck-pier pounding force.

Solving the differential equations according to a continuous condition, namely, $u(L, 2 L / c)=(V L / \beta c)[1-\exp (-2 \beta)]$, we have

$$
\begin{aligned}
u(L, t) & \\
= & \frac{V L}{\beta c}\left[2 \exp \left(-\frac{\beta c t}{L}+2 \beta\right)-\exp \left(-\frac{\beta c t}{L}\right)-1\right] \\
& -\frac{4 V L}{c} \exp \left(-\frac{\beta c t}{L}+2 \beta\right) \\
& +2 V t \exp \left(-\frac{\beta c t}{L}+2 \beta\right) .
\end{aligned}
$$

$$
R(\tau)= \begin{cases}1-\exp (-\beta \tau) & 0 \leq \tau \leq 2 \\ 2 \exp (-\beta \tau+2 \beta)-4 \beta \exp (-\beta \tau+2 \beta)+2 \beta \tau \exp (-\beta \tau+2 \beta)-\exp (-\beta \tau)-1 & 2<\tau \leq 4\end{cases}
$$

And the time history of the pounding force is

$$
\begin{aligned}
P(t) & \\
= & \frac{E A V}{c}\left[2 \exp \left(-\frac{\beta c t}{L}+2 \beta\right)-\exp \left(-\frac{\beta c t}{L}\right)-1\right] \\
& -\frac{4 \beta E A V}{c} \exp \left(-\frac{\beta c t}{L}+2 \beta\right) \\
& +\frac{2 \beta E A V}{L} t \exp \left(-\frac{\beta c t}{L}+2 \beta\right) .
\end{aligned}
$$

Introducing dimensionless pounding force $R(t)=$ $P(t) c / E A V$ and dimensionless time coordinate $\tau=c t / L$, the time history of the dimensionless pounding force using the one-dimensional wave theory is as follows:
According to (10), time histories of the deck-pier pounding force for different $\beta$ can be drawn in Figure 4 .

As shown in Figure 4, for minor $\beta$, the deck-pier pounding force curve is close to a sinusoidal curve. And for major $\beta$, the deck-pier pounding force curve is close to a rectangular curve.

The second model is based on a simplified SDOF method. In the method, the axial stiffness of the deck is assumed to be far larger than the pier stiffness, which is usually valid and practical. Therefore, the deck is regarded as a rigid body and simulated by a particle with the deck mass and the pier is simulated by a spring as shown in Figure 5. $m$ and $k$ are the deck mass and the pier stiffness in the figure.

For the simplified SDOF method, the circular frequency of the time history of the deck-pier pounding force is

$$
\omega=\sqrt{\frac{\beta E A / L}{\rho A L}}=\frac{c}{L} \sqrt{\beta}
$$




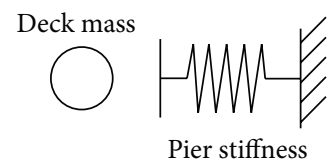

FIGURE 5: A simplified SDOF theoretical model for the deck-pier pounding issue.

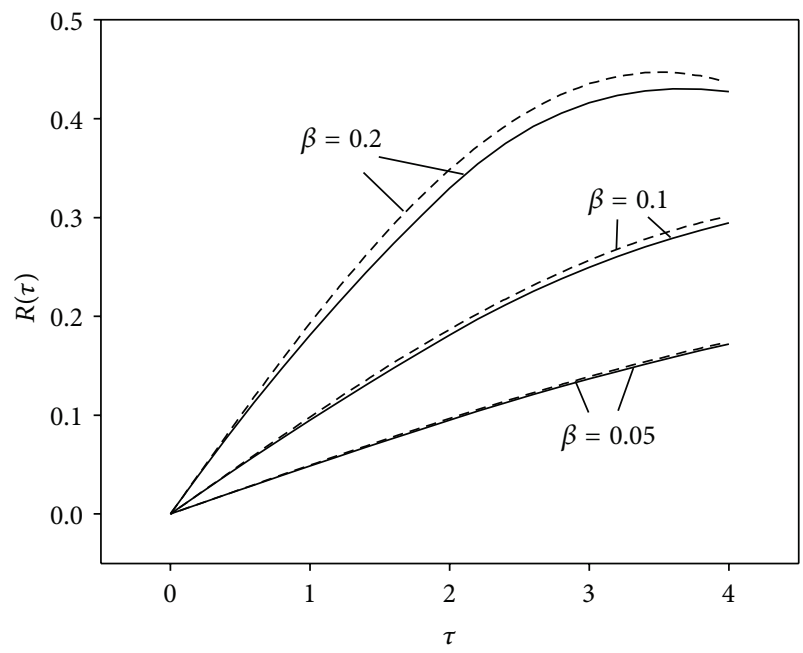

(a)

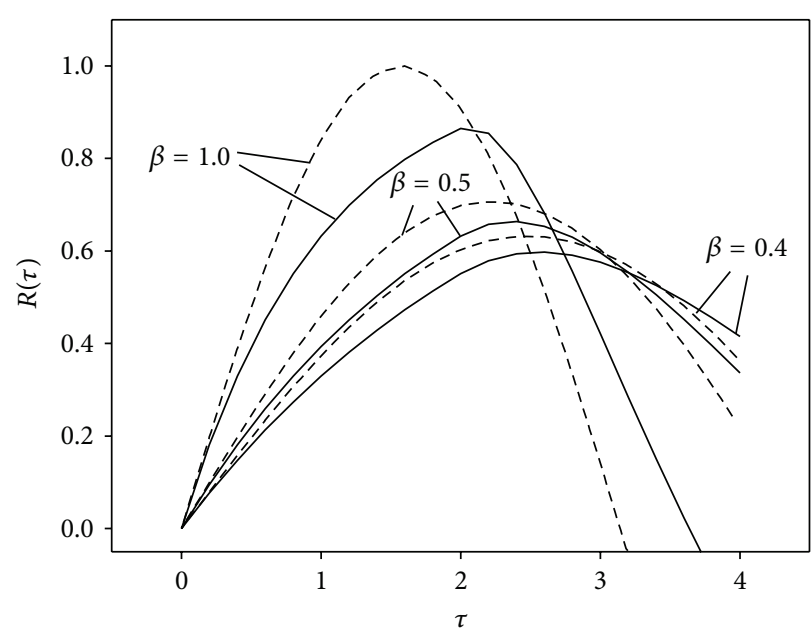

(b)

FIGURE 6: Comparisons of pounding force time histories between two theoretical models.

Then, time histories of the pounding force and the dimensionless pounding force are as follows:

$$
\begin{aligned}
P(t) & =\sqrt{\beta} \frac{E A V}{c} \sin \left(\frac{c t}{L} \sqrt{\beta}\right), \\
P_{\max } & =\sqrt{\beta} \frac{E A V}{c}=\sqrt{\frac{k_{p} L}{E A}} \frac{E A V}{\sqrt{E / \rho}}=V \sqrt{\rho A L \cdot k_{p}} \\
& =V \sqrt{m \cdot k_{p}}, \\
R(\tau) & =\sqrt{\beta} \sin (\sqrt{\beta} \tau) .
\end{aligned}
$$

Time histories of the pounding force obtained using two theoretical methods are compared in Figure 6. Solid lines indicate results of the one-dimensional wave theory, and broken lines indicate those of the simplified SDOF method. As shown, for minor $\beta$, results of the simplified SDOF method agree well with those of the one-dimensional wave theory. However, for major $\beta$, such as $\beta \geq 0.4$, differences between the results are remarkable. Therefore, the deck should not be regarded as a rigid body when the pier stiffness is close to the axial stiffness of the deck.

Also as shown in Figure 6, as the axial flexibility of the deck is considered in the one-dimensional wave theory, the pounding duration will be extended and the peak pounding force will be reduced.

It should be noted that the simplified SDOF theoretical model is linear and no energy dissipation is considered. Therefore, if the pier is damaged heavily or much energy is dissipated during the pounding process, the simplified SDOF method is no more applicable.

\section{Experimental Study of Deck-Pier Pounding}

Shaking table tests were conducted in the State Key Laboratory of Disaster Reduction in Civil Engineering, Tongji University, to verify the simplified SDOF method for the deckpier pounding issue. Two shaking tables, named Table B and Table C, were included to simulate ground motions.

A simply supported bridge was used as the test specimen and consisted of two piers, four bearings, and a deck as shown in Figure 7. The two piers were installed on Table B and Table C, respectively. Each pier consisted of two columns and one crossbeam. The columns were fixed on the table, and the crossbeam was bolted on tops of columns. Four load transducers were placed on the two crossbeams. On each load transducer, one Double Spherical Seismic Isolation bearing (DSSI bearing) was placed. The DSSI bearing was developed by substituting the flat sliding surface of an ordinary spherical sliding bearing with a spherical sliding surface. Its working mechanism in earthquakes was similar to a Friction Pendulum Sliding (FPS) bearing. The deck was supported on the four bearings and steel plates were bolted on the deck to achieve an additional mass of 100 tons.

Steel blocks were installed on the connection plates of bearings on Table B to restrict excessive bearing displacements as shown in Figure 8. A certain horizontal distance was designed between the block and the side of the upper bearing plate, which was named Clearance in this paper. 

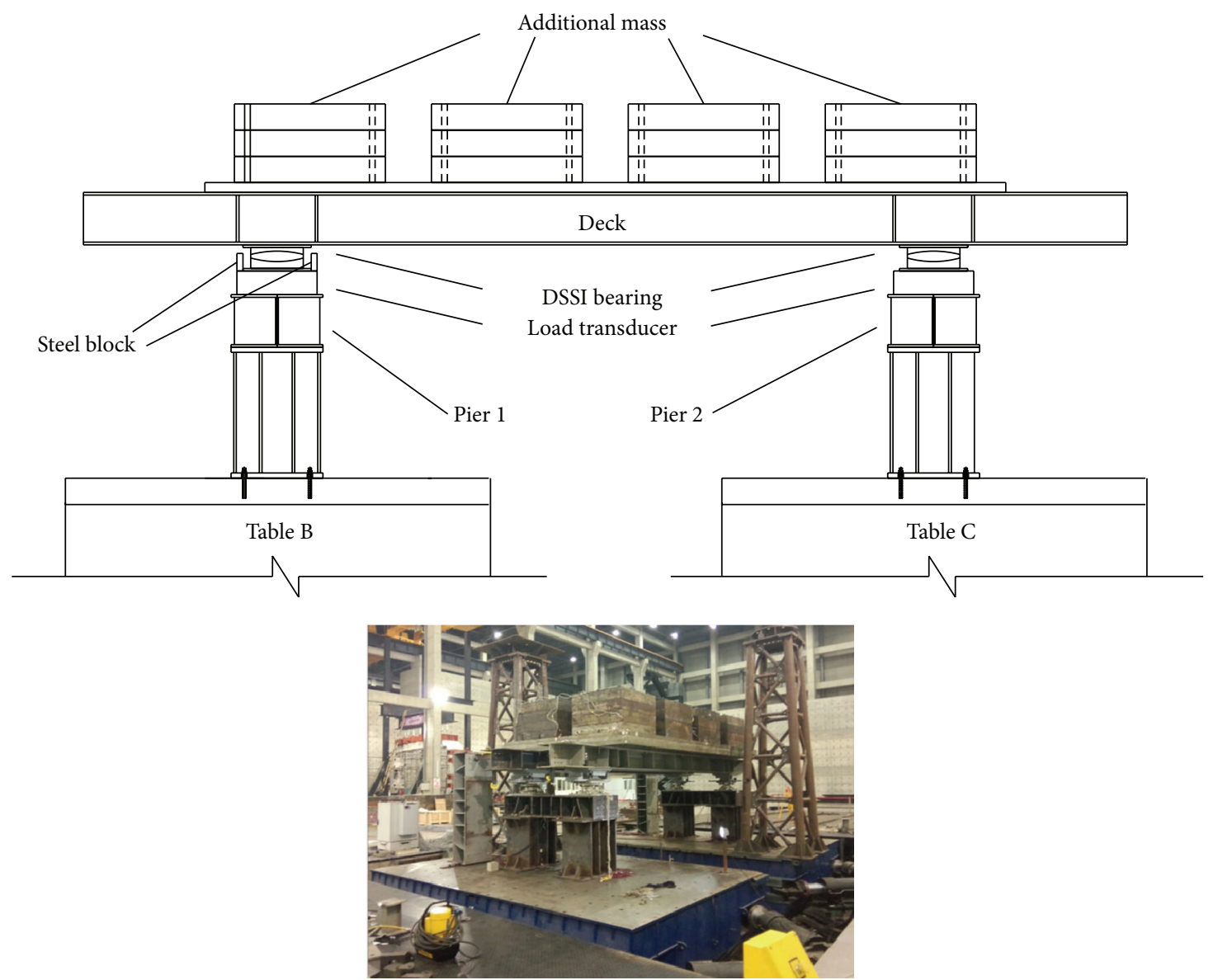

FIGURE 7: The test setup and specimen.

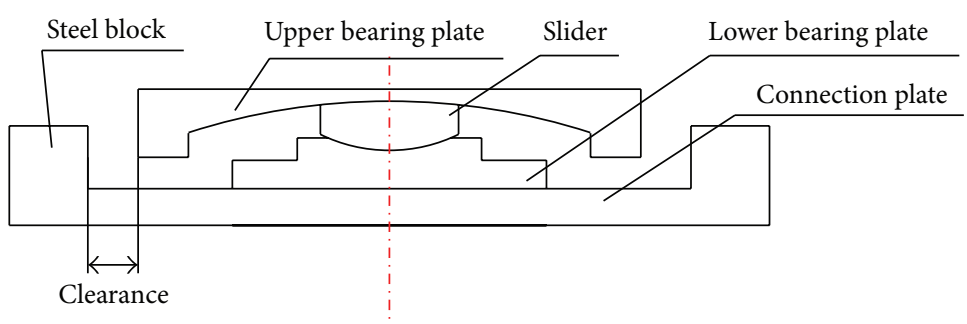

FIGURE 8: Configuration of a bearing with shear pins used as a fixed bearing.

A record of Wenchuan Earthquake as shown in Figure 9 was input in the cases. The motion was recorded in the $E$ $W$ direction in Wolong, Sichuan Province. The peak ground acceleration is $948 \mathrm{gal}$.

Four shaking table test cases were arranged and listed in Table 1. As shown, the peak ground acceleration was scaled down in order not to damage load transducers.

In Cases 1 and 3, a rubber plate was inserted in each Clearance to study the applicability of the method for different pounding stiffness, so pounding stiffness of these two cases was lower.

Responses of the bridge model were measured by 33 transducers collecting data from the bridge model with a sampling frequency of $512 \mathrm{~Hz}$. Bearing displacements were
TABle 1: Test cases.

\begin{tabular}{lcc}
\hline Cases & Clearance & Peak acceleration \\
\hline 1 & $10 \mathrm{~mm}$ & $0.2 \mathrm{~g}$ \\
2 & $20 \mathrm{~mm}$ & $0.2 \mathrm{~g}$ \\
3 & $50 \mathrm{~mm}$ & $0.5 \mathrm{~g}$ \\
4 & $60 \mathrm{~mm}$ & $0.5 \mathrm{~g}$ \\
\hline
\end{tabular}

measured by 8 displacement transducers, bearing forces were measured by 4 load transducers, and acceleration for the tables, decks, and piers was measured by 21 accelerometers.

In Figures 10-12, time histories of displacements, forces, and relative velocities of bearings on Table B in all the four 


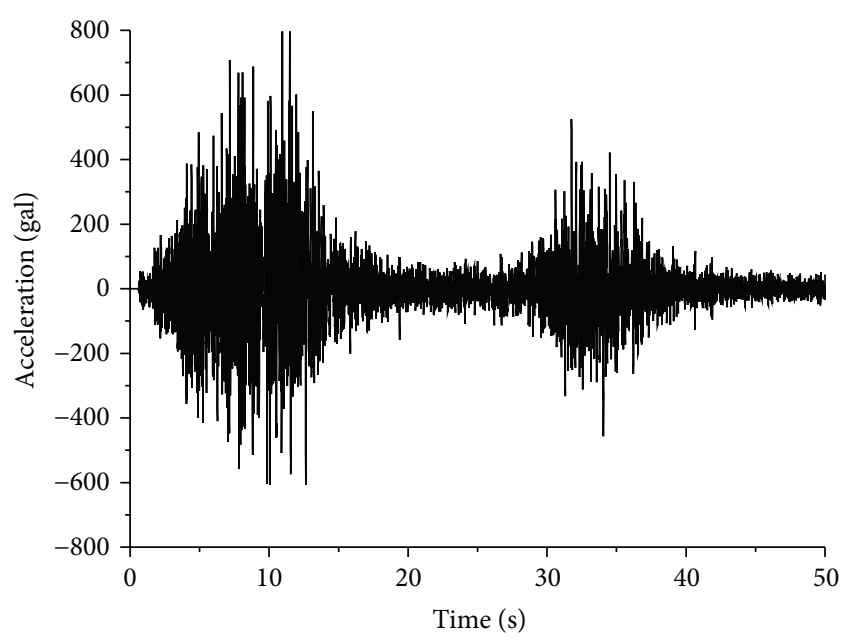

(a) A ground acceleration record of Wenchuan Earthquake

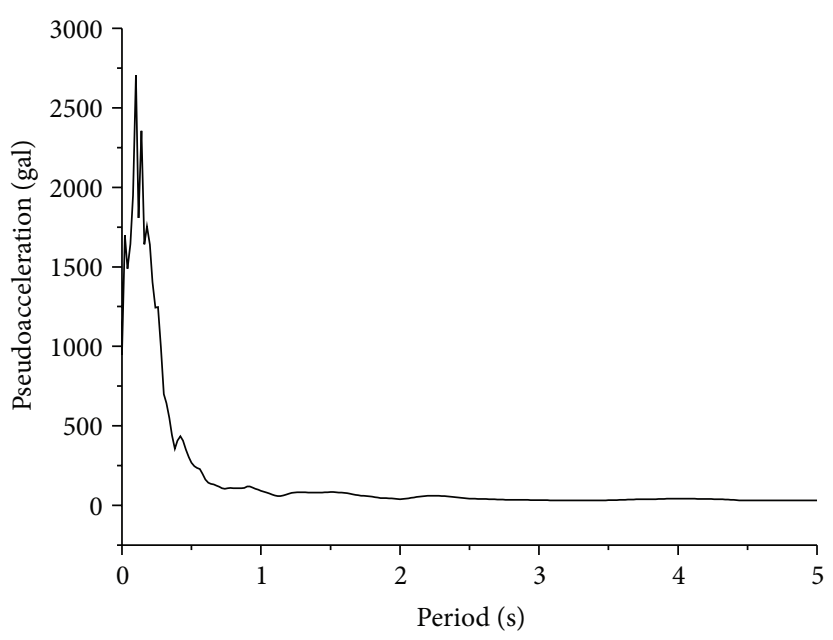

(b) Pseudoacceleration response spectra (5\% damping)

FIGURE 9: A record of Wenchuan Earthquake used in the cases.

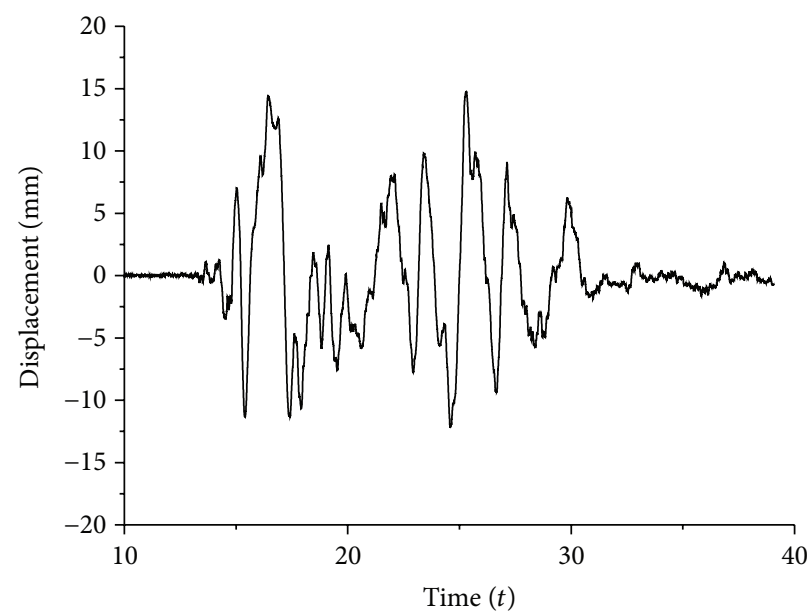

(a) Case 1

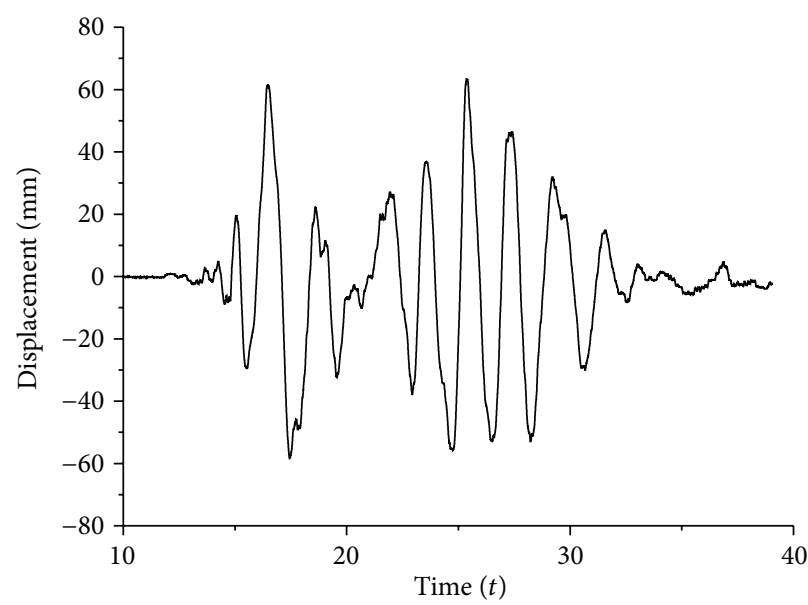

(c) Case 3

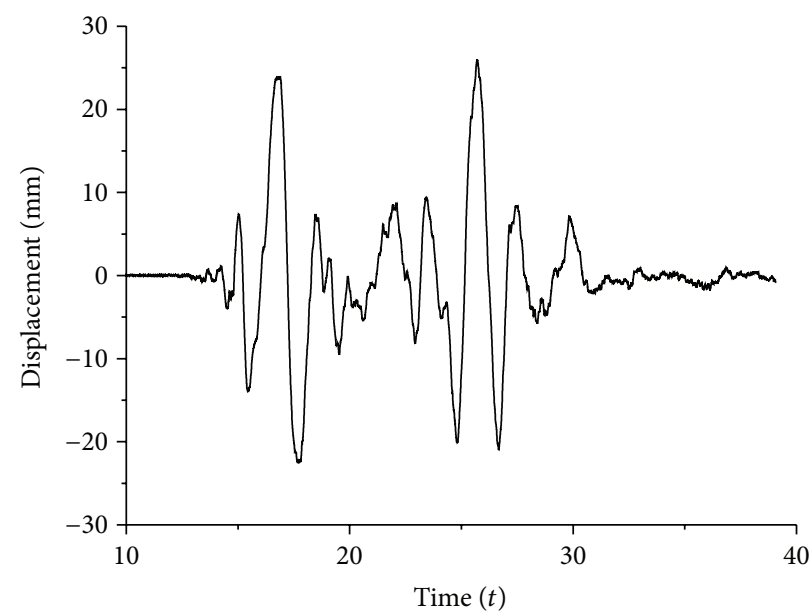

(b) Case 2

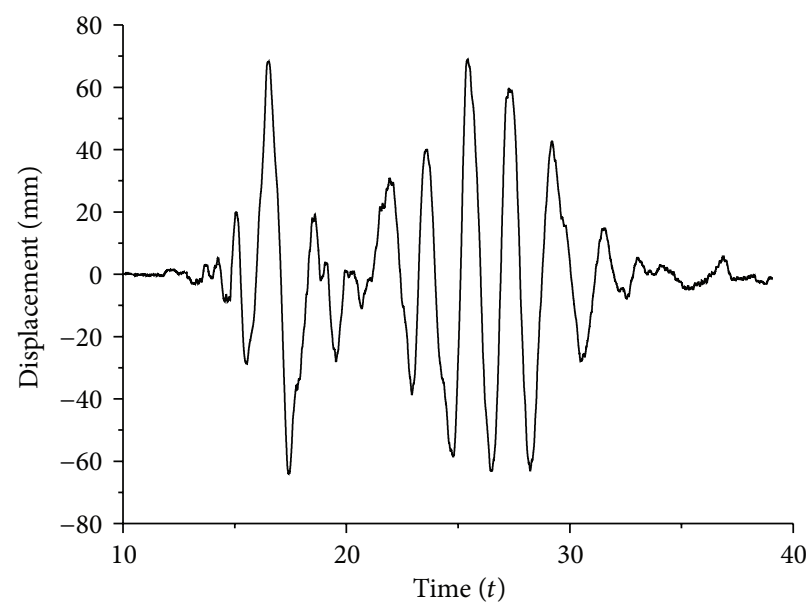

(d) Case 4

Figure 10: Time histories of bearing displacements on Table B in all the cases. 


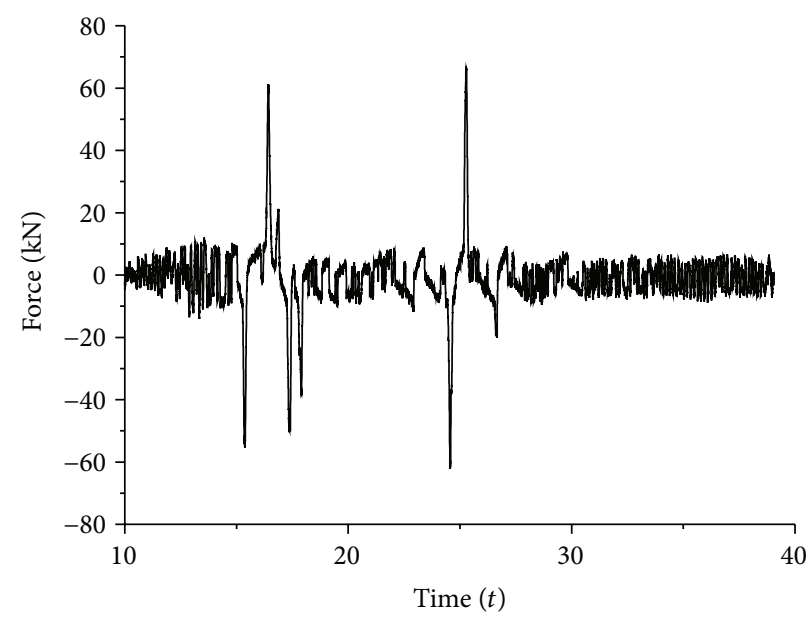

(a) Case 1

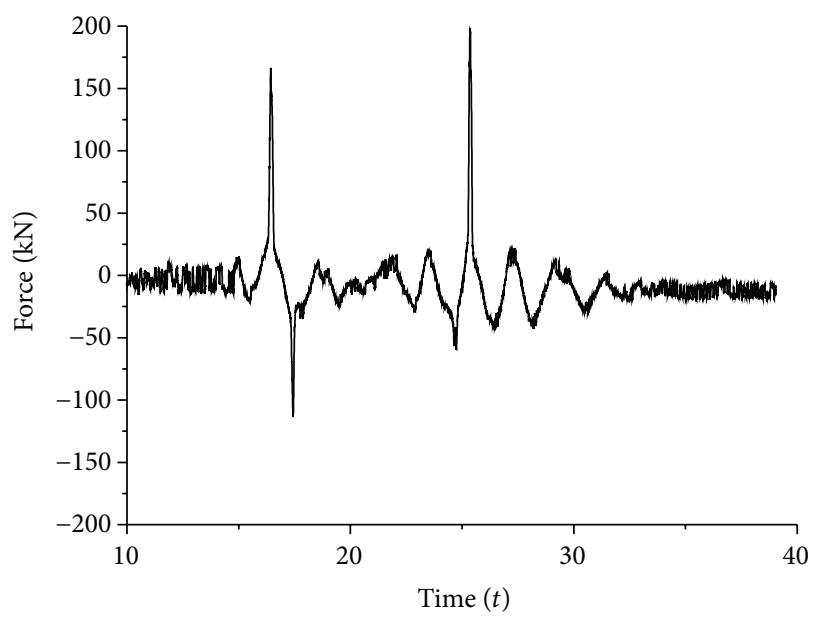

(c) Case 3

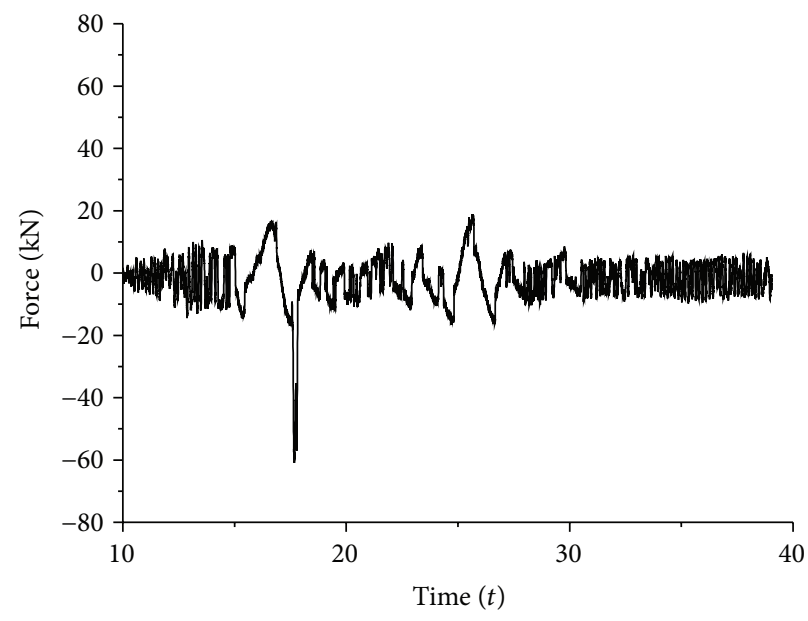

(b) Case 2

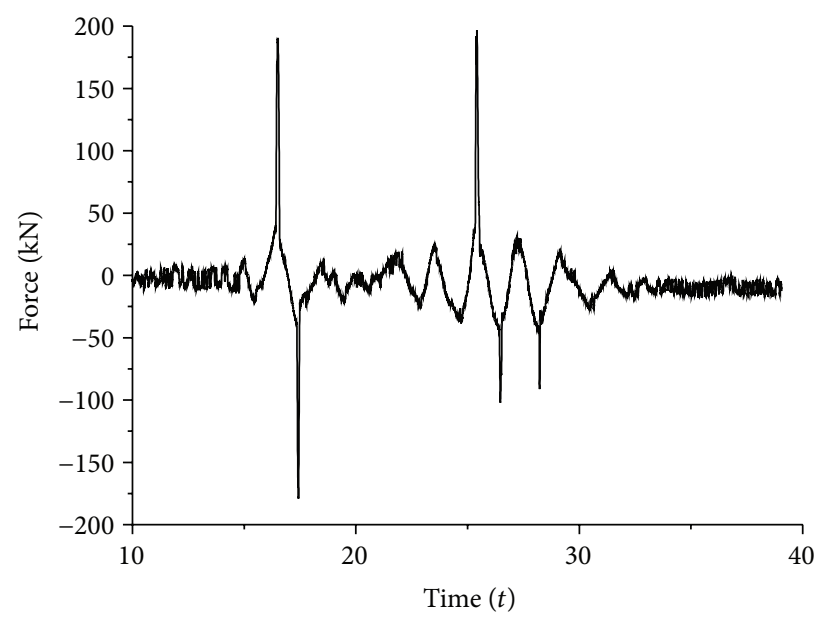

(d) Case 4

Figure 11: Time histories of bearing forces on Table B in all the cases.

cases are shown. The bearing displacement is the average value of two bearings, the bearing force is the resultant force of two bearings, and the relative velocity is the derivative of the bearing displacement.

In order to verify the simplified SDOF method, (13) is used to calculate the theoretical pounding force for each pounding, and then the theoretical pounding force $F_{\text {theoretical }}$ is compared with the test pounding force $F_{\text {test }}$.

The theoretical pounding force is calculated and listed in Table 2. $m$ is the pounding mass and equals 100 tons for all the cases. $k$ is the pounding stiffness and equals the pounding force divided by the displacement measured in the test. Once the pounding happens, bearing relative velocity drops rapidly. The bearing relative velocity just before the moment of pounding is extracted as the pounding velocity $V$.

As shown, errors between theoretical pounding forces and test pounding forces are less than $20 \%$, so the simplified SDOF method is verified. By the comparison, it is found that the deck can be simulated as a particle and the simplified
SDOF method can be used to study the deck-pier pounding issue.

Because no energy dissipation is considered in the model, the simplified SDOF method may overestimate the actual pounding force and the theoretical pounding force is always larger than the test pounding force. Therefore, the simplified SDOF method can provide a reasonable upper limit of pounding forces. The actual pounding force is also influenced by energy dissipation and damage condition during the pounding process.

\section{FEM Analysis of the Deck-Pier Pounding Issue}

In order to study pounding responses under longitudinal earthquakes and the applicability of the simplified SDOF method, a typical simply supported girder bridge is studied. The span is $16 \mathrm{~m}$, and piers are both $5 \mathrm{~m}$ high. The left end of the deck is supported on two same expansion bearings, and 


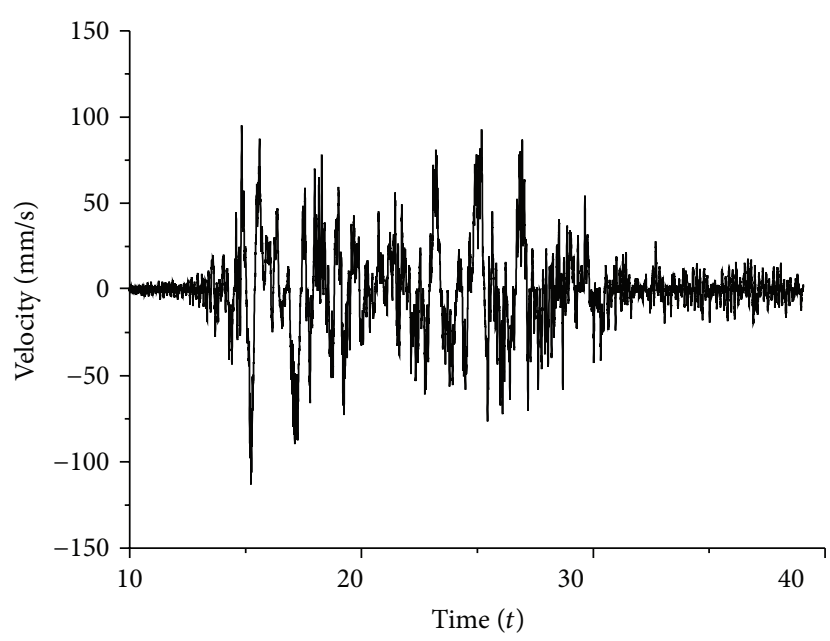

(a) Case 1

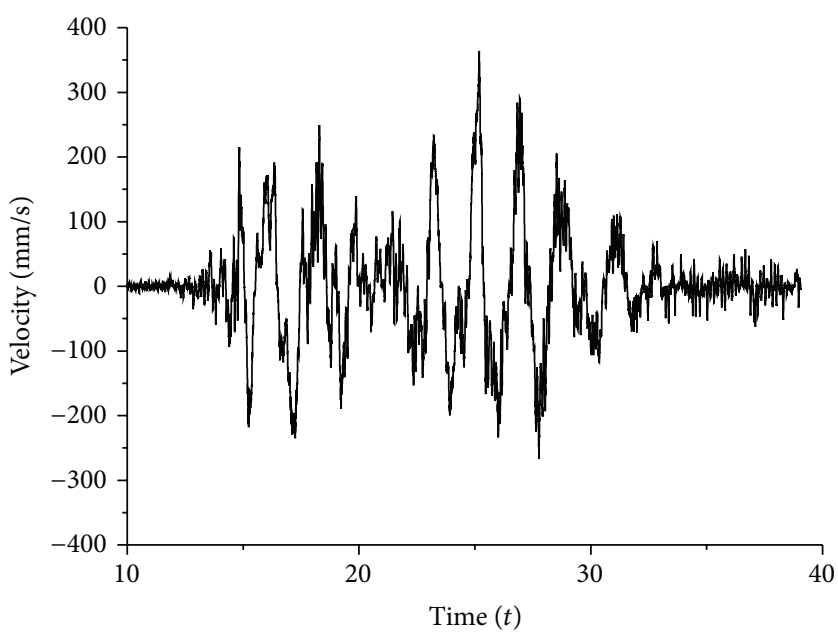

(c) Case 3

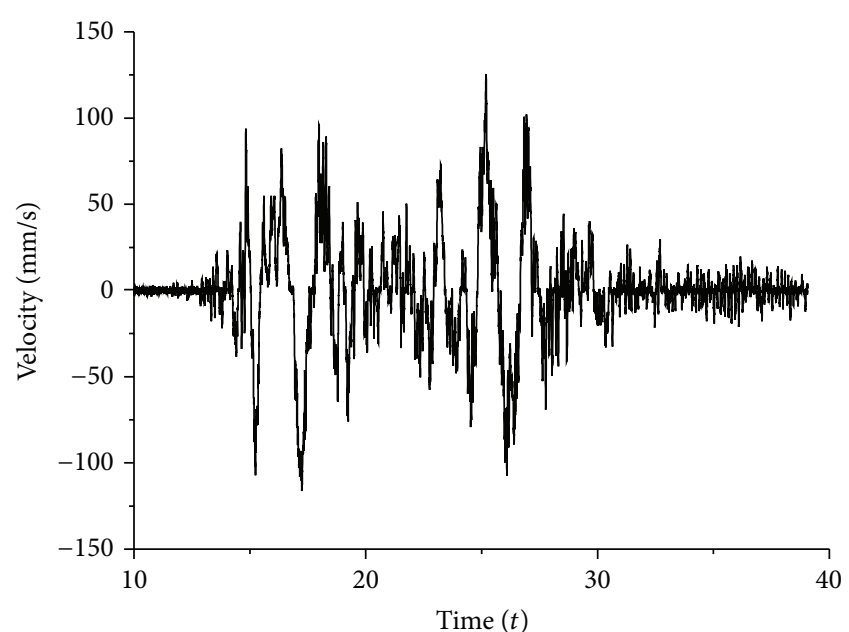

(b) Case 2

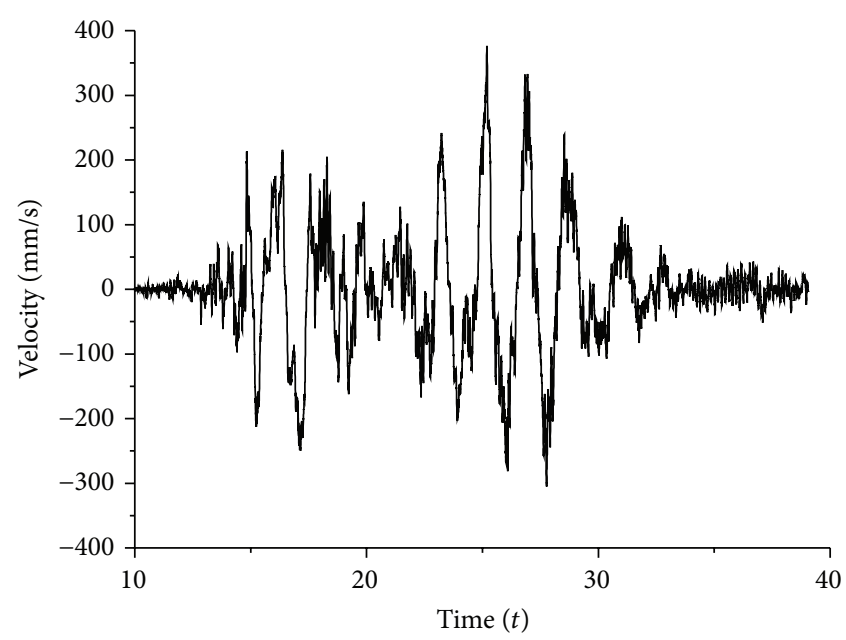

(d) Case 4

FIgURE 12: Time histories of bearing velocities on Table B in all the cases.

TABLE 2: Comparisons of theoretical pounding forces and test pounding forces.

\begin{tabular}{|c|c|c|c|c|c|c|c|}
\hline Case & Pounding number & $m$ (ton) & $k(\mathrm{kN} / \mathrm{mm})$ & $V(\mathrm{~mm} / \mathrm{s})$ & $F_{\text {theoretical }}(\mathrm{kN})$ & $F_{\text {test }}(\mathrm{kN})$ & Error (\%) \\
\hline 1 & 1 & 100 & 10.77 & -58.61 & -60.81 & -55.33 & $9.91 \%$ \\
\hline 1 & 2 & 100 & 12.65 & 57.08 & 64.20 & 61.24 & $4.83 \%$ \\
\hline 1 & 3 & 100 & 11.33 & -55.81 & -59.42 & -50.20 & $18.38 \%$ \\
\hline 1 & 4 & 100 & 13.91 & -55.40 & -65.33 & -62.17 & $5.08 \%$ \\
\hline 1 & 5 & 100 & 12.31 & 64.63 & 71.70 & 67.08 & $6.89 \%$ \\
\hline 2 & 1 & 100 & 50.25 & -30.89 & -69.24 & -60.96 & $13.58 \%$ \\
\hline 3 & 1 & 100 & 10.01 & 170.79 & 170.92 & 166.57 & $2.61 \%$ \\
\hline 3 & 2 & 100 & 8.48 & -143.78 & -132.43 & -113.73 & $16.44 \%$ \\
\hline 3 & 3 & 100 & 14.15 & 187.00 & 222.47 & 197.86 & $12.44 \%$ \\
\hline 4 & 1 & 100 & 45.89 & 104.47 & 223.78 & 190.45 & $17.50 \%$ \\
\hline 4 & 2 & 100 & 65.46 & -80.90 & -206.98 & -179.05 & $15.60 \%$ \\
\hline 4 & 3 & 100 & 51.95 & 98.35 & 224.18 & 191.96 & $16.78 \%$ \\
\hline 4 & 4 & 100 & 50.71 & -51.28 & -115.48 & -102.24 & $12.95 \%$ \\
\hline 4 & 5 & 100 & 55.14 & -46.39 & -108.94 & -91.16 & $19.50 \%$ \\
\hline
\end{tabular}




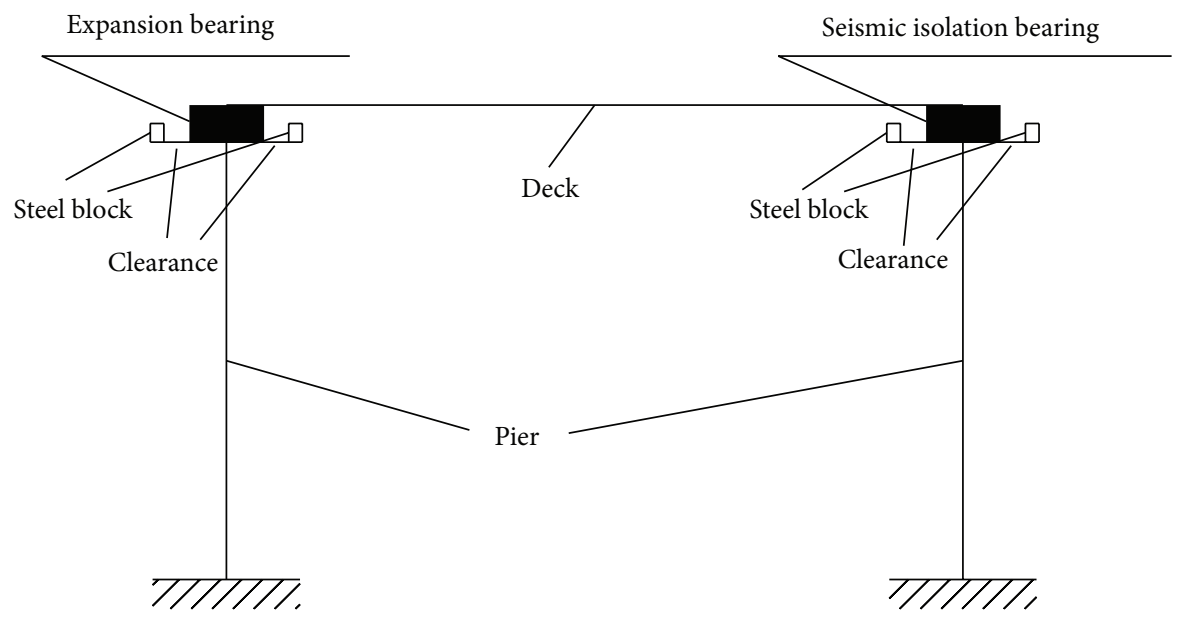

(a) The whole structural model

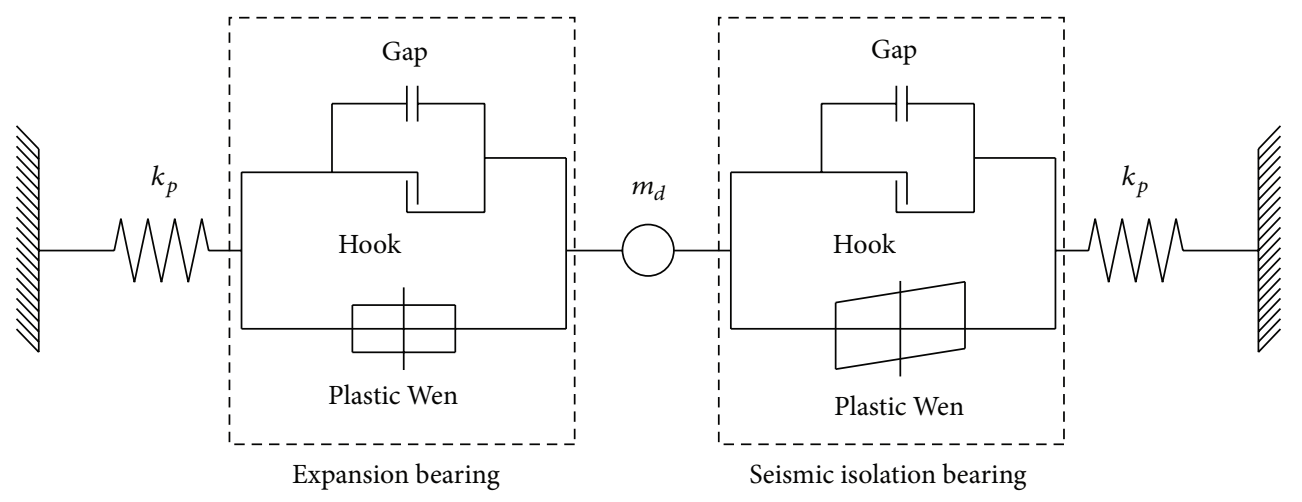

(b) The SDOF model

Figure 13: Models of a simply supported girder bridge.

TABLE 3: Parameters of a simply supported girder bridge model.

\begin{tabular}{ll}
\hline Components & Parameters \\
\hline Deck & Elasticity modulus is $3.45 \times 10^{7} \mathrm{kPa}$, density is $2.5 \mathrm{ton} / \mathrm{m}^{3}$, and cross-sectional area is $5.4 \mathrm{~m}^{2}$ \\
Pier & Elasticity modulus is $3.45 \times 10^{7} \mathrm{kPa}$, density is $2.5 \mathrm{ton} / \mathrm{m}^{3}$, and cross-sectional area is $2.0 \mathrm{~m}^{2}$ \\
Expansion bearing & $\begin{array}{l}\text { Horizontal stiffness before yielding is } 4.32 \times 10^{4} \mathrm{kN} / \mathrm{m} \text {, yield force is } 43.2 \mathrm{kN} \text {, and horizontal stiffness after yielding } \\
\text { is } 0\end{array}$ \\
$\begin{array}{l}\text { Seismic isolation } \\
\text { bearing }\end{array}$ & $\begin{array}{l}\text { Horizontal stiffness before yielding is } 4.32 \times 10^{4} \mathrm{kN} / \mathrm{m} \text {, yield force is } 43.2 \mathrm{kN} \text {, and horizontal stiffness after yielding } \\
\text { Steel block }\end{array}$ \\
\hline
\end{tabular}

the right end of the deck is supported on two same seismic isolation bearings. Steel blocks for unseating prevention are installed on both sides of each bearing. Clearances are all set to be $0.1 \mathrm{~m}$ for all the steel blocks. Deck-pier poundings will happen between the deck and steel blocks under longitudinal earthquakes until bearing displacements exceed the preserved Clearances.

4.1. Analysis Models and Seismic Input. Two models of the simply supported girder bridge are established with the FEM software SAP2000. One is a whole structural model and the other one is a SDOF model. For the whole structural model, all the components are simulated as shown in Figure 13(a). The deck and piers are simulated with frame elements. Bearings are simulated with Plastic Wen link elements. Steel blocks are simulated with gap and hook link elements. All the elements and their parameters are listed in Table 3. For the SDOF model, pier masses are neglected and the deck mass is concentrated on a particle as shown in Figure 13(b). $k_{p}$ represents the horizontal stiffness of piers, and the deck mass $m_{d}$ is 216 tons.

Sinusoidal acceleration wave is input as the seismic excitation for simplicity. Peak acceleration is $4 \mathrm{~m} / \mathrm{s}^{2}$, frequency is $1 \mathrm{~Hz}$, duration is $5 \mathrm{~s}$, and integration step is $1 \mathrm{~ms}$. 


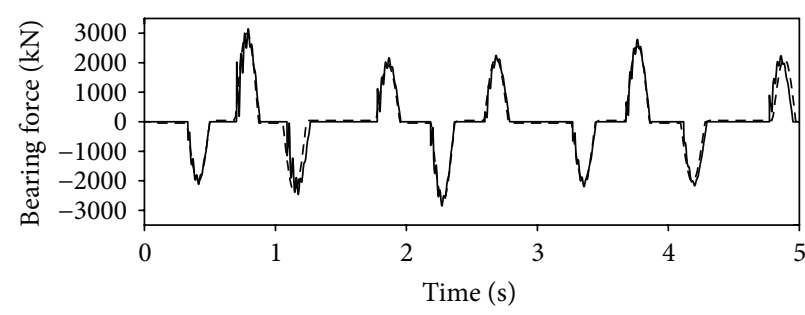

(a) $\beta=0.0034$

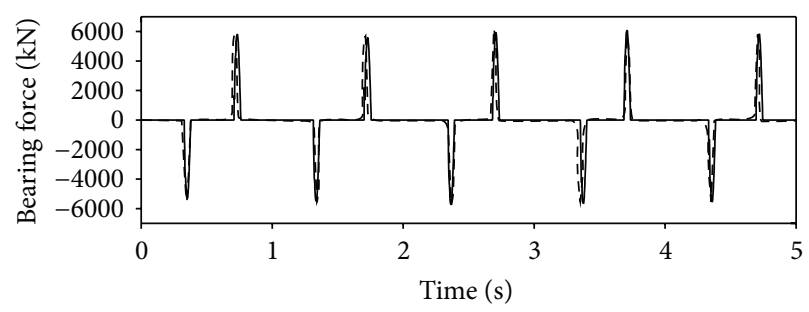

(c) $\beta=0.034$

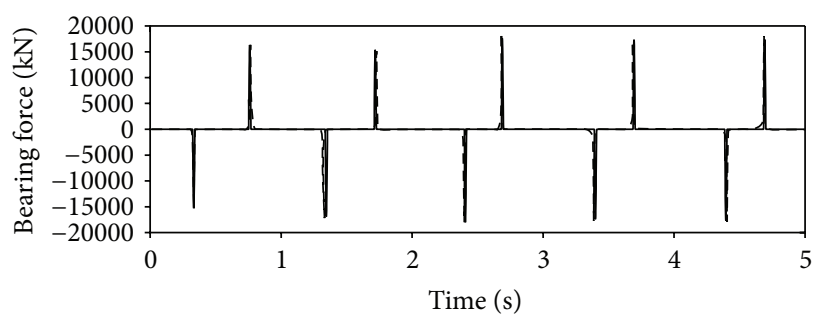

(e) $\beta=0.345$

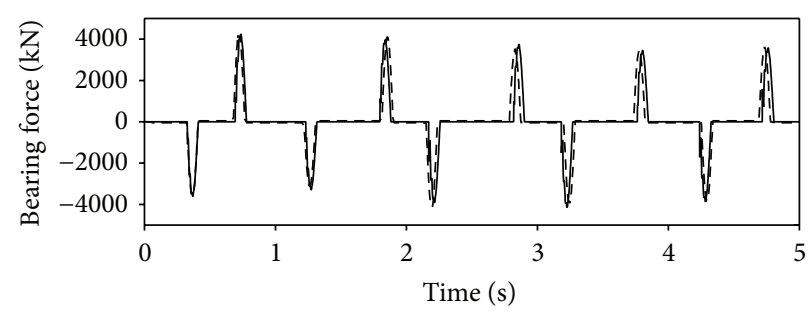

(b) $\beta=0.0138$

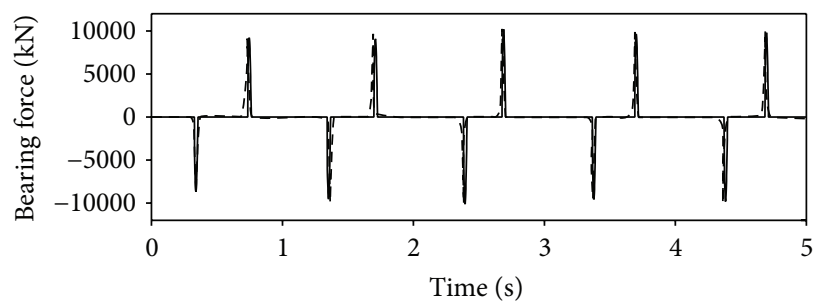

(d) $\beta=0.103$

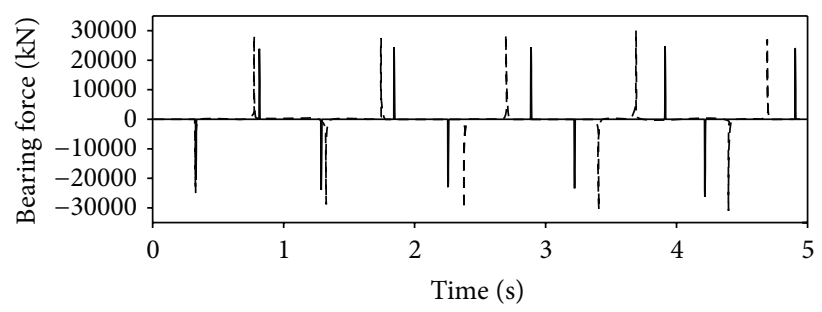

(f) $\beta=1.0$

FIGURE 14: Force time histories of the expansion bearing.

4.2. Applicability of the Simplified SDOF Method. To evaluate the applicability of the simplified SDOF method, results of the SDOF model for different pier stiffness are compared with those of the whole structural model. The influence of the pier stiffness on pounding response is studied by altering the elastic modulus of piers. The horizontal stiffness is designed to be $4.0 \times 10^{4} \mathrm{kN} / \mathrm{m}, 1.6 \times 10^{5} \mathrm{kN} / \mathrm{m}, 4.0$ $\times 10^{5} \mathrm{kN} / \mathrm{m}, 1.2 \times 10^{6} \mathrm{kN} / \mathrm{m}, 4.0 \times 10^{6} \mathrm{kN} / \mathrm{m}$, and $1.16 \times$ $10^{7} \mathrm{kN} / \mathrm{m}$, respectively. The axial stiffness of the deck is $1.16 \times$ $10^{7} \mathrm{kN} / \mathrm{m}$. So stiffness ratios are $0.0034,0.0138,0.034,0.103$, 0.345 , and 1.0 , respectively.

Force time histories of the expansion bearing of the two models are shown in Figure 14. The expansion bearing force is composed of the friction force and the pounding force, and the latter is far larger than the former. In the figure, solid lines indicate results of the whole structural model, and broken lines indicate results of the SDOF model.

Every spike in Figure 14 indicates one pounding between the deck and the pier. As shown, along with the increase of the pier stiffness, the pounding duration becomes shorter and the pounding force becomes larger. Differences between the two models are very small, except for $\beta=1.0$. The pounding force and the pounding time of the two models are almost the same for the first five cases. Therefore, the SDOF model can estimate the pounding force fairly accurately for $\beta<$ 0.345 at least. All the peak pounding forces calculated by the SDOF model are larger than those of the whole structural model, which is similar to the theoretical results. It needs to be noted that $\beta=0.345$ is already very big pier stiffness and applicability of the simplified SDOF method is verified for almost all the bridges.

For $\beta=1.0$, differences of the pounding force and the pounding time between the two models are much larger than other cases. So the SDOF model is not applicable anymore. However, because the horizontal stiffness of bridge pier is always much less than the axial stiffness of the deck, $\beta=1.0$ is a very rare condition.

4.3. Influences of the Pier Stiffness and the Pier Mass on Pounding Responses. The influence of the pier horizontal stiffness on pounding responses is studied by altering the elastic modulus of piers as mentioned in Section 4.2. The influence of the pier mass on pounding responses is studied by altering the density of piers. Pier masses are designed to be 5 tons, 10 tons, 25 tons, 50 tons, and 125 tons, respectively, which are named as M1 to M5.

The maximum pounding responses of the whole structural model are shown in Figure 15.

As shown, the pounding force will increase and the deck displacement will decrease with the increase of the pier stiffness. The influence of the pier mass on the deck displacement is very small.

For minor pier stiffness, the influence of the pier mass on the pounding force is also not too much, so the pier mass can 


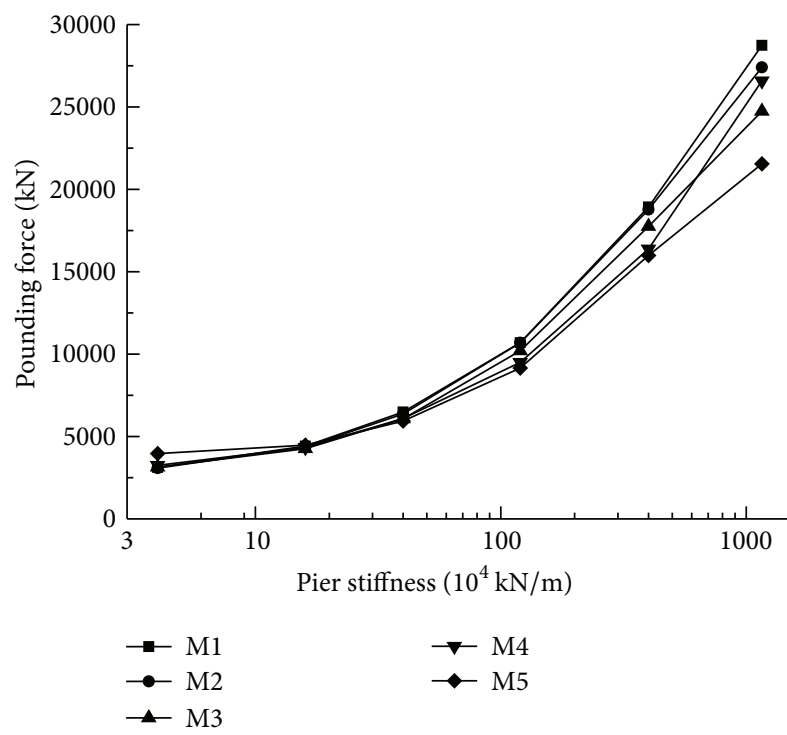

(a) Maximum pounding forces

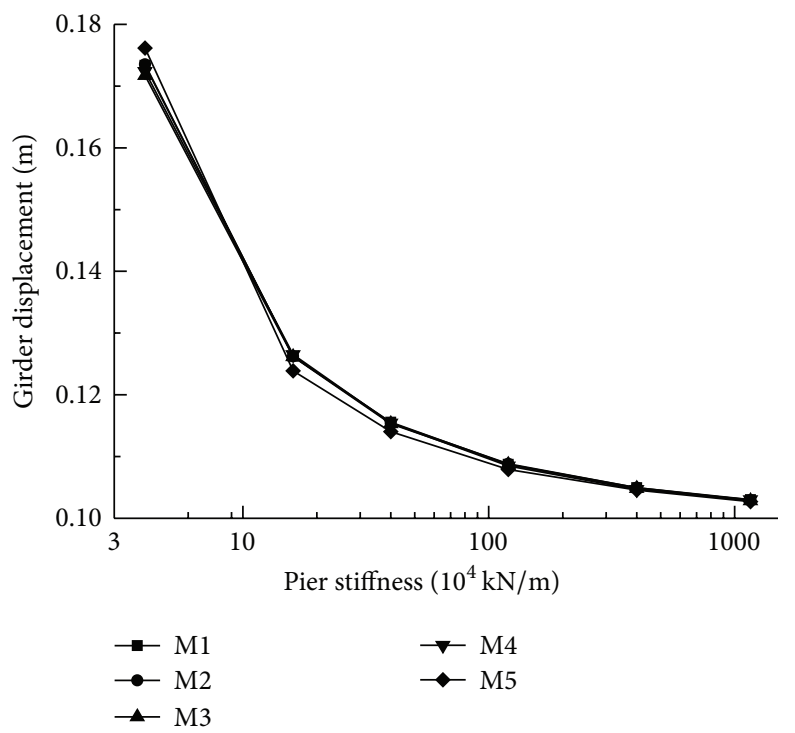

(b) Maximum deck displacements

FIGURE 15: Maximum pounding responses.

be neglected and the SDOF model is applicable. However, the influence of the pier mass on the pounding force is bigger for major pier stiffness, and so the pier mass is not negligible and the SDOF model is no more applicable.

\section{Conclusions}

In this paper, theoretical analysis, shaking table test, and finite element analysis were conducted to study the deck-pier pounding issue; the following conclusions are drawn:

(1) Based on theoretical results and test results, it was found that the longitudinal deck-pier pounding issue can be simulated by the simplified SDOF method if energy dissipation is negligible and the pier stiffness is much less than the axial stiffness of the deck.

(2) It was found that the pounding duration becomes shorter and the pounding force becomes larger along with the increase of the pier stiffness.

(3) The pier mass has little effect on pounding responses except for bridges with very rigid piers.

\section{Competing Interests}

The authors declare that they have no competing interests.

\section{Acknowledgments}

This work was supported in part by National Natural Science Foundation of China (no. 51278372) and the Ministry of Science and Technology of China, Grant no. SLDRCE 14-B15.

\section{References}

[1] W. Goldsmith, Impact, Dover, New York, NY, USA, 2001.

[2] G. Cole, R. Dhakal, A. Carr, and D. Bull, "An investigation of the effects of mass distribution on pounding structures," Earthquake Engineering and Structural Dynamics, vol. 40, no. 6, pp. 641-659, 2011.

[3] H. Hao, K. Bi, N. Chouw, and W.-X. Ren, "State-of-the-art review on seismic induced pounding response of bridge structures," Journal of Earthquake and Tsunami, vol. 7, no. 3, Article ID 1350019, 2013.

[4] B. F. Maison and K. Kasai, "Analysis for a type of structural pounding," Journal of Structural Engineering, vol. 116, no. 4, pp. 957-977, 1990.

[5] B. F. Maison and K. Kasai, "Dynamics of pounding when two buildings collide," Earthquake Engineering and Structural Dynamics, vol. 21, no. 9, pp. 771-786, 1992.

[6] R. Jankowski, K. Wilde, and Y. Fujino, "Pounding of superstructure segments in isolated elevated bridge during earthquakes," Earthquake Engineering and Structural Dynamics, vol. 27, no. 5, pp. 487-502, 1998.

[7] K. T. Chau and X. X. Wei, "Pounding of structures modelled as non-linear impacts of two oscillators," Earthquake Engineering and Structural Dynamics, vol. 30, no. 5, pp. 633-651, 2001.

[8] S. Muthukumar and R. DesRoches, "A Hertz contact model with non-linear damping for pounding simulation," Earthquake Engineering and Structural Dynamics, vol. 35, no. 7, pp. 811-828, 2006.

[9] P. Komodromos, P. C. Polycarpou, L. Papaloizou, and M. C. Phocas, "Response of seismically isolated buildings considering poundings," Earthquake Engineering and Structural Dynamics, vol. 36, no. 12, pp. 1605-1622, 2007.

[10] K. Ye, L. Li, and H. Zhu, "A note on the Hertz contact model with nonlinear damping for pounding simulation," Earthquake Engineering and Structural Dynamics, vol. 38, no. 9, pp. 11351142, 2009. 
[11] C. C. Patel and R. S. Jangid, "Dynamic response of adjacent structures connected by friction damper," Earthquake and Structures, vol. 2, no. 2, pp. 149-169, 2011.

[12] R. Jankowski, "Non-linear FEM analysis of pounding-involved response of buildings under non-uniform earthquake excitation," Engineering Structures, vol. 37, pp. 99-105, 2012.

[13] D. G. Weng, C. Zhang, X. L. Lu, S. Zeng, and S. M. Zhang, "A simplified design procedure for seismic retrofit of earthquakedamaged RC frames with viscous dampers," Structural Engineering and Mechanics, vol. 44, no. 5, pp. 611-631, 2012.

[14] G. Watanabe and K. Kawashima, "Numerical simulation of pounding of bridge decks," in Proceedings of the 13th World Conference on Earthquake Engineering, Paper No. 884, Vancouver, Canada, August 2004.

[15] E. G. Dimitrakopoulos, "Seismic response analysis of skew bridges with pounding deck-abutment joints," Engineering Structures, vol. 33, no. 3, pp. 813-826, 2011.

[16] B. Li, K. Bi, N. Chouw, J. W. Butterworth, and H. Hao, "Effect of abutment excitation on bridge pounding," Engineering Structures, vol. 54, pp. 57-68, 2013.

[17] C.-J. Wang and M.-H. Shih, "Performance study of a bridge involving sliding decks and pounded abutment during a violent earthquake," Engineering Structures, vol. 29, no. 5, pp. 802-812, 2007.

[18] Y. Huo and J. Zhang, "Effects of pounding and skewness on seismic responses of typical multispan highway bridges using the fragility function method," Journal of Bridge Engineering, vol. 18, no. 6, pp. 499-515, 2013.

[19] K. Bi and H. Hao, "Numerical simulation of pounding damage to bridge structures under spatially varying ground motions," Engineering Structures, vol. 46, pp. 62-76, 2013.

[20] S. E. Abdel Raheem, "Pounding mitigation and unseating prevention at expansion joints of isolated multi-span bridges," Engineering Structures, vol. 31, no. 10, pp. 2345-2356, 2009.

[21] B. Li and N. Chouw, "Experimental investigation of inelastic bridge response under spatially varying excitations with pounding," Engineering Structures, vol. 79, pp. 106-116, 2014.

[22] S.-H. Kim and M. Shinozuka, "Effects of seismically induced pounding at expansion joints of concrete bridges," Journal of Engineering Mechanics, vol. 129, no. 11, pp. 1225-1234, 2003.

[23] M. J. N. Priestley, F. Seible, and G. M. Calvi, Seismic Design and Retrofit of Bridges, John Wiley \& Sons, New York, NY, USA, 1996. 


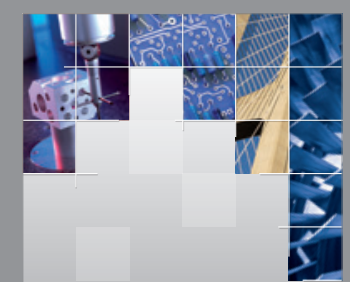

\section{Enfincering}
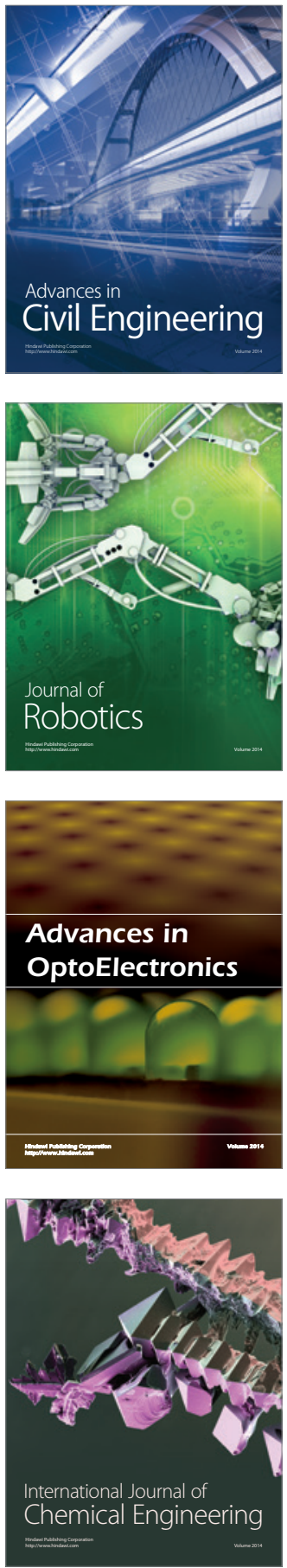

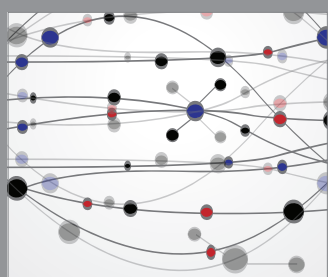

The Scientific World Journal

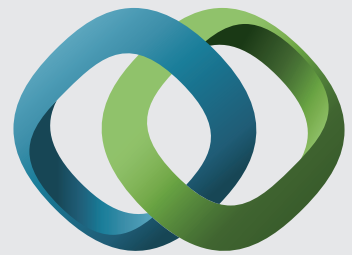

\section{Hindawi}

Submit your manuscripts at

http://www.hindawi.com
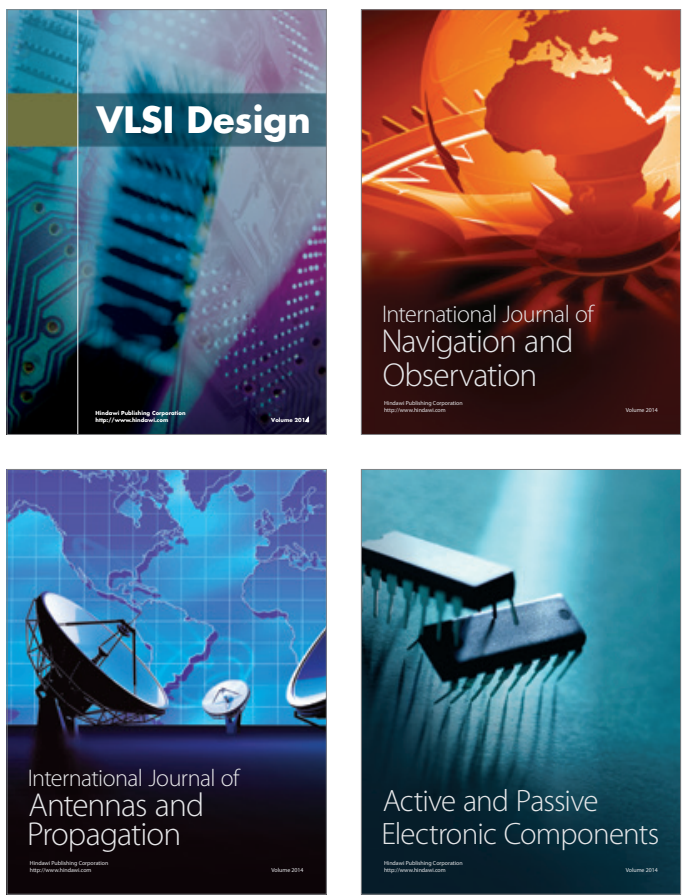
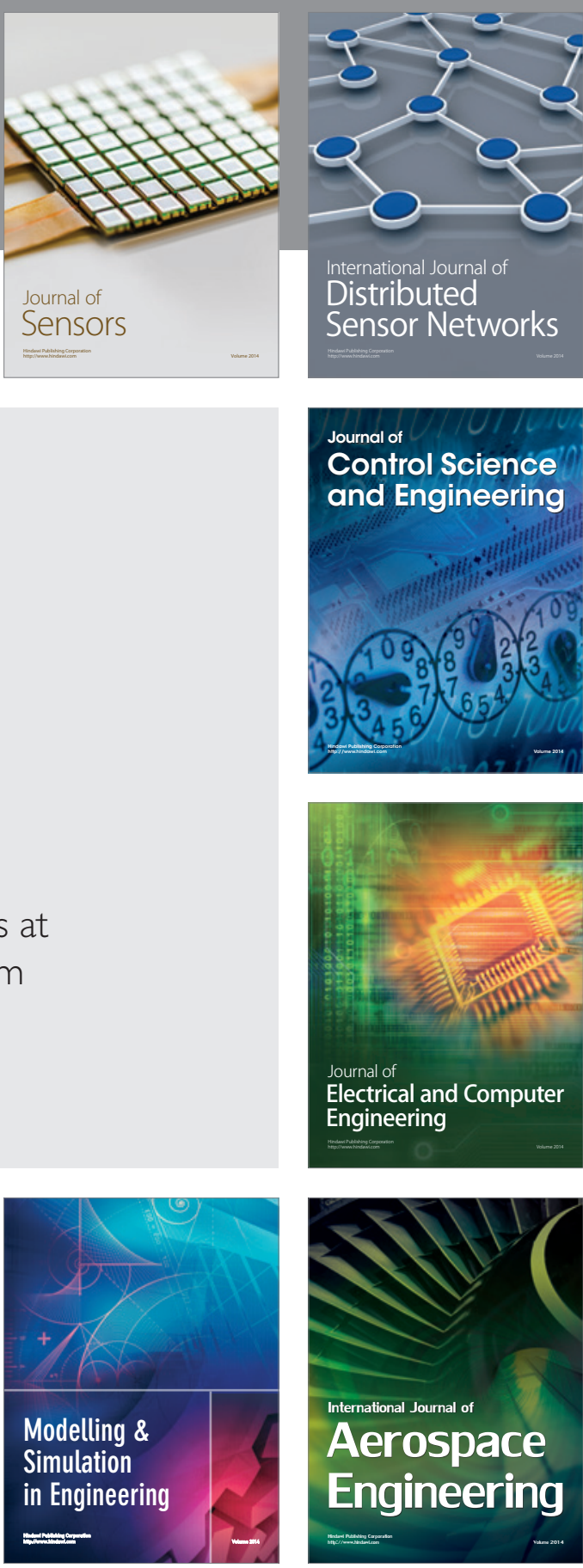

International Journal of

Distributed

Sensor Networks

Journal of

Control Science

and Engineering
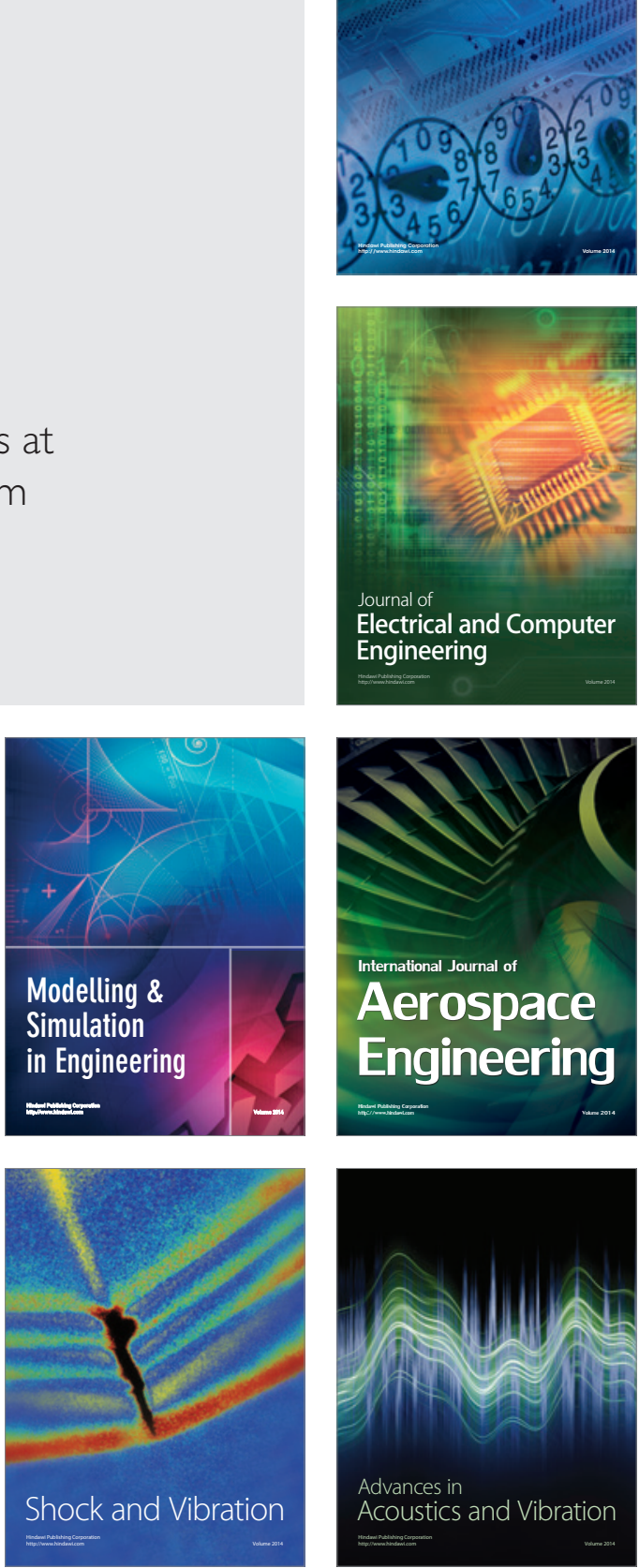